Academy Sponsored Report

\title{
New Antimalarial Drug Discovery in India and Future Strategy for Malaria Control
}

\author{
G P DUTTA* \\ Ex-Director's Grade Scientist-G and CSIR Emeritus Scientist, CSIR-Central Drug Research Institute, \\ Lucknow; 9, Shyam Nagar, Khurram Nagar, Lucknow 226 022, India
}

(Received on 31 July 2015; Revised on 14 October 2015; Accepted on 28 January 2016)

\begin{abstract}
This INSA commissioned report on "New antimalarial drug discovery in India and future strategy for malaria control" focuses on development of : (A) new fast-acting blood schizontocides which could (1) control the multidrug resistant strains of Plasmodium falciparum/P. vivax, (2) reduce high malaria related mortality among complicated/comatose cerebral malaria cases, and (3) save children dying due to severe malaria; (B) safe anti-relapse (Radical Curative) drugs for $P$. vivax/ $P$. ovale, to replace toxic primaquine (which is the only drug in clinical use for the last six decades); (C) new Transmission Blocking Drugs which prevent the spread of multidrug resistant $P$. falciparum: primaquine is the only transmission blocking drug that sterilizes gametocytes in man (vertebrate host) and thus interrupts transmission of $P$. falciparum but which is contraindicated for infants, children and pregnant women and G-6-PD deficient red cell cases by World Health Organization Safety Committees; (D) safe 8-aminoquinolines (to replace primaquine) which do not cause methaemoglobinaemia, cyanosis, hemolytic anaemia; (E) effective antimalarials for emerging artemisinin resistance/MDR strains of $P$. falciparum and $P$. vivax; (F) a safe antimalarial drug for pregnancy, and (G) a safe effective ACT drug combination for control of uncomplicated/ MDR $P$. falciparum infections. During the past five years, nearly 32 Malaria Eradication Agenda sponsored by International Malaria Experts have expressed that the present armamentarium may not achieve malaria eradication or prevent malaria related mortality because of lack of effective antimalarials. CSIR-Central Drug Research Institute has developed the following new antimalarials which will be helpful to achieve some of the malarial control/eradication objectives: (a) FastActing Blood Schizontocides like $\alpha / \beta$-Arteether (patented 1990), $\alpha$-Arteether, $\beta$-Arteether (in groundnut oil), Dihydroartemisinin (patented Internationally in Sixteen Countries, 1999 and 2000), Dihydroartemisinin and Piperaquine (ACT approved by WHO 2010), $\alpha / \beta$-artelinate (patented in 1989), Pyronaridine (2000), Synthetic 1,2,4-Trioxanes (Fenozan), Azithromycin, Tafenoquine (a broad spectrum antimalarial) (jointly developed by WRAIR and CDRI 1988); (b) New Leads for Gametocytocidal Drugs: Artemisinin which kills $P$. cynomolgi B gametocytes in anopheles mosquitoes (1989), $\alpha / \beta$-Arteether as intra-muscular (single) or oral dose for P. cynomolgi B. (1990, 1996), Sod. $\beta$-artelinate (1996); (c) New Safe Leads: gametocytocidal/transmission blocking drugs Tafenoquine (WR 238605), Bulaquine (CDRI 80/53) (2005) gametocytocidal for P. falciparum; (d) New Anti-Relapse Drugs (Hypnozoiticidal) as safe substitutes for Primaquine: CDRI 80/53/Elubaquine/Bulaquine (1989, patented), Aablaquine (Bulaquine + Chloroquine) (patented, 2000), Tafenoquine (WR 236805, 1988); (e) New Causal Prophylactic Drugs: Bulaquine (Elubaquine), Tafenoquine (WR 238605) and (f) Rectal Suppositories as Pre-Referal Emergency Treatment for children suffering from severe malaria/cerebral malaria: $\alpha / \beta$ Arteether (CDRI-CIMAP Joint Patent 2001), Dihydroartemisinin (CDRI-CIMAP Joint Patent 1999 and 2000).
\end{abstract}

Keywords : Antimalarial; Drug Discovery; Blood Schizontocidal; Artemisinins; Plasmodium yielii nigeriensis (MDR); Malaria Eradication; Transmission Blocking

\section{Introduction}

\section{Historical Background}

This report has been prepared in order to focus on the country's progress in the field of antimalarial drug discovery for malaria control in India, specifically for the development of new powerful antimalarials for controlling/eradicating the emerging MDR virulent strains of Plasmodium falciparum and P. vivax

*Author for Correspondence: E-mail: duttag123@yahoo.com 
relapsing malaria. The other objective was to highlight the development of emergency treatment for the patients dying of complicated/comatose cerebral malaria complications specially to save millions of children dying of malaria. Even after hundred years of Sir Ronald Ross's Noble Prize (1902) winning discovery in India, showing that malaria is transmitted by mosquitoes, there was urgency to develop safer gametocytocidal (transmission blocking) drugs which can be used as safe primaquine substitutes in malaria treatment. First priority at the Central Drug Research Institute (CDRI) was to develop reliable technologies for drug discovery including the multi-drug resistance (MDR) screening of experimental models which can select most active antimalarials for treatment of multidrug resistant malaria patients resistant to available drugs.

\section{Historical Account of Global Malaria Eradication Agenda and Control Strategy in India}

The project aimed at 'Eradication of Malaria' was proposed by Hoffman (1917). By 1950, the World Health Organization experts proposed the strategy that the malaria eradication could be achieved by blocking malaria transmission through the application of insecticide DDT to end the further spread of malaria and through the elimination of reservoirs of gametocyte carriers. It was conceived that malaria control could be achieved through the mass chloroquine treatment of Plasmodium falciparum combined with DDT insecticide sprays. The National Malaria Eradication Programme (NMEP) that was launched in 1958 in India was successful in bringing down malaria cases from 75 million per year to less than one hundred thousand and in preventing malaria deaths by 1965. From 1965 onwards, there were reports of increase in malaria cases and also emergence of chloroquine resistant $P$. falciparum together with DDT resistance in anopheline malaria vectors. The NMEP during 1976-1977 decided to implement modified malaria control programme in the country under "Modified Plan of Operation". Indian Council of Medical Research (ICMR) has provided research support to the programme by sponsoring research projects that would help the programme. Extensive clinical trials of antimalarials were carried out and emergence of resistance to chloroquine and other antimalarials was recorded by NMEP in different parts of the country. The CSIR-Central Drug Research Institute (CSIR-CDRI), which was made the centre for antimalarial drug development, has since then remained committed to promoting global malaria control programmes.

\section{Drug Discovery and Emergence of Drug Resistance in Malaria and Strategy for Artemisinin Based Combination Therapy (ACT) Options for Control of Multidrug Resistant Malaria (MDR)}

Powerful antimalarials (blood schizontocides) were discovered between 1880 and 1990 including quinine (discovered in 1880), artemisinin (Qinghao) (1969), mepacrine (1930), chloroquine (1934), proguanil (1944), primaquine (1945), amodiaquine (1946), pyrimethamine (1952), pyronaridine (1970), mefloquine (1971), Metakelfin (1975), Fansidar (1975), Fansimef (1980), quinine + tetracycline (1970) and halofantrine (1990) for control of Plasmodium falciparum. Within a short span of their clinical use, the malignant form of the parasite (P. falciparum), which causes mortality, had the ability to develop resistance against most of these drugs. By 1999-2000, the World Health Organization and international clinical scientists in malaria endemic countries realized the impending danger of emerging artemisinin resistance in clinical trials in which artemisinin/artesunate/ artemether/dihydroartemisinin etc. were found to fail when used as monotherapy for $P$. falciparum treatment resulting in the increase in malaria mortality exponentially. The WHO (1998) issued an international alert to stop using artemisinins monotherapy for malignant form of $P$. falciparum throughout the malaria endemic regions of the globe. WHO recommendations (2006 and 2007) further made it obligatory for all governments/national antimalaria control agencies in malaria endemic countries to introduce ACTs as the most potential drug combinations for efficient malaria treatment, besides controlling the mortality and ensuring the elimination of multidrug resistant $P$. falciparum. The five ACT combinations recommended by WHO for multidrug resistant $P$. falciparum malaria treatment and control are listed below:
(i) Artesunate + Amodiaquine
(ii) Artesunate + Mefloquine 
(iii) Artesunate + Sulfadoxine + Pyrimethamine

(iv) Artemether + Lumefantrine

(v) Dihydroartemisinin + Piperaquine

According to the WHO guidelines, Artemisinin derivatives alone cannot be recommended as monotherapy for $P$. falciparum (uncomplicated malaria or complicated severe malaria) because of danger of emergence of artesunate resistance (Sahr et al., 2001; Luxemburger, 1998). Cases of artemisinin resistant $P$. falciparum have already been reported from several South-East Asian countries (Noedl et al., 2005, 2008; Afonso et al., 2006; Dondorp et al., 2009; Inselburg, 1985; Eckstein-Ludwig et al., 2003). Another ACT combination Coartem (a combination of Artemether + Lumefantrine) used for control of $P$. falciparum in Africa was reported to have failed in treated cases in Africa because of emergence of Coartem resistance (Hastings and Ward, 2005). Martensson et al. (2005) and Siswath et al., (2005) also reported a significant increase in the mutation of $P$. falciparum and Pf mdr1 $86 \mathrm{~N}$ was observed in treated cases indicating emerging resistance in clinical cases treated with Coartem (ACT combination of Artemether + Lumefantrine).

The World Health Organization Report (2013) has also focused on the problems of emerging threat of $P$. falciparum developing artemisinins/ACTs resistance in several South-East Asian countries. They have also argued that it may not be feasible to control artemisinin resistance with the available ACTs.

\section{WHO (2013): Question and Answers on Artemisinin Resistance}

The WHO (2013) has cautioned the South-East Asian countries (Cambodia, Myanmar, Thailand and Vietnam) where artemisinin resistance appeared earlier and was documented by WHO. The WHO has strongly advocated that artemisinin-based monotherapies should not be used alone in order to prolong the effective use of ACT combinations (Resolution World Health Assembly, 60.18, 2007). The WHO has also strongly emphasized the need to stop ongoing malaria transmission to contain emergence of artemisinin resistance. The WHO (2013) has finally expressed the view that "if resistance were to spread to - or emerge in - India or sub-Saharan Africa, the public health consequences could be dire, as no alternative antimalarial medicine is available at present with the same level of efficacy and tolerability as ACTs". The WHO (2013) has further warned that "there is, therefore, a limited window of opportunity to avert a regional public health disaster, which could have severe global consequences". In author's opinion, limited clinical trials with 3-4 dose $\alpha / \beta$-arteether (IM) alone may be a better choice to evaluate in areas where artesunate/artemisinin resistance has been reported.

\section{Approaches}

\section{Technology Developed for Primary Antimalarial Drug Screening}

The original chloroquine resistant strain of Plasmodium yoelii nigeriensis (N67) and $P$. knowlesi $\mathrm{W} 1$ (non-gametocyte producing strain) were procured by late Professor P C C Garnham from London School of Hygiene and Tropical Medicine and brought safely to CSIR-Central Drug Research Institute, Lucknow on August 21, 1976.

Rodent Malaria Parasite $-P$. yoelii nigeriensis (MDR strain was selected at CDRI) has been used for drug discovery (Antimalarial Primary Screening) at CDRI by the Author. The MDR strain selected at CDRI is $100 \%$ fatal in Swiss mice $(20 \pm 2 \mathrm{~g})$. This strain was exposed to a large variety of standard drugs listed below and designated as $P$. yoelii nigeriensis (MDR strain) (developed by the author). It has been extensively used at CDRI for drug discovery of new antimalarial blood schizontocides.

P. yoelii nigeriensis (MDR Strain) shows high level of multi-drug resistance to the following antimalarials, antibiotics and antimalarial-antibiotic combinations:

Chloroquine, Amodiaquine, Mefloquine, Mepacrine, Quinine, Quinidine, Halofantrine, Pyrimethamine, WR238605, Tetracycline, Demeclocycline, Doxycycline, Erythromycin, Ciprofloxacin, Norfloxacin, Chloroquine + Tetracycline, Amodiaquine + Tetracycline, Mefloquine + Tetracycline, Mepacrine + Tetracycline, Quinine + Tetracycline, Quinine + Oxytetracycline, Quinine + Doxycycline, Quinine + Erythromycin, Ciprofloxacine + Chloroquine, Norfloxacine + Chloroquine, Quinidine 
+ Tetracycline. For details of the resistance levels of $P$. yoelii nigeriensis MDR to antibiotics and drug plus antibiotic combinations using the four days treatment schedule, see Dutta et al., 2001).

\section{Primate Antimalarial Secondary Screening Models for New Antimalarials}

Protocols established for antimalarial screening against primate malaria at CDRI include the following test systems which led to the selection of new drugs:

1. Blood-schizontocidal activity (P. cynomolgi Brhesus monkey, $P$. knowlesi-rhesus monkey, $P$. coatneyi-rhesus monkey and $P$. fragile-rhesus monkey $(\alpha / \beta$-Arteether, Dihydroartemisinin, DHA)

2. Anti-relapse activity (P. cynomolgi BAnopheles stephensi-rhesus monkey (CDRI 80/53/Bulaquine=Elubaquine), Aablaquine, Tafenoquine

3. Causal-prophylactic activity (P. cynomolgi B/ A. stephensi-rhesus monkey (Bulaquine $=$ Elubaquine, Ablaquine, Tafenoquine)

4. Gametocytocidal/sporontocidal activity $(P$. cynomolgi/A. stephensi-rhesus monkey (Artemisinin, $\alpha / \beta$-arteether, Dihydroartemisinin (DHA), CDRI 80/53 (Bulaquine=Elubaquine) and Tafenoquine)

The above mentioned experimental rhesus monkey models have been successfully used for the last forty years for the screening and identification of blood schizontocides, new 8-aminoquinolines as primaquine substitutes (for anti-relapse activity) and to develop new gametocytocidal (transmission blocking drugs).

The primate antimalaria screening programme for anti-relapse (Radical Curative) tests with Plasmodium cynomolgi $\mathrm{B}$ transmission through Anopheles stephensi has led to the discovery of two new anti-relapse drugs listed below:

Discovery of Tafenoquine (WR 238605) as Primaquine Substitute (1988)

Anti-relapse activity was first reported by Milhous et al. (1988) as part of CDRI-Walter Reed Collaboration.

\section{Discovery of CDRI 80/53 (Bulaquine/ Elubaquine (1989) as safest anti-relapse/ gametocytocidal (transmission blocking primaquine substitute)}

Compound 80/53 (Bulaquine/Elubaquine) was reported by Dutta et al. (1989c) and Puri et al. (1989).

Aablaquine $=$ Bulaquine + Chloroquine combination was first reported in CDRI Patent 501/ MUM/2000 Grant 31.05.2000 IN, Mumbai.

\section{Maintenance of $P$. cynomolgi B Strain in Rhesus Monkey}

P. cynomolgi B, procured in 1979 from late Professor W E Collins, CDC, Atlanta, has been maintained in rhesus monkey at CDRI by successive blood induced passages or by cryopreservation. Since November 1982 to 1993 , the parasite was regularly transmitted through Anopheles stephensi mosquitoes or through the cryopreserved strain from time to time.

\section{Large Scale Sporozoite Production for Monkey Inoculation}

Colony bred Anopheles stephensi were fed on different days on the gametocyte carrying monkeys and the infectivity of mosquitoes as determined by oocyst count on day 8 post-feeding was recorded. Following the day of sporozoite inoculation, the mean prepatent period was $8.58 \pm 0.87$ days, the primary asexual peak was attained on day $8.38 \pm 2.27$ and the secondary peak on day $15.15 \pm 2.63$ after patency. Infectivity rate was $100 \%$ in 144 batches of mosquitoes. The high oocyst count was obtained between day 12 and day 18 after patency. Infective gametocyte peak coincided with the secondary asexual peak parasitaemia, with the result that maximum oocyst number was observed in batches fed on the day of secondary peak or one day prior to or one day after the secondary peak. Infectivity during the period of primary asexual peak was inconsistent. Yield of approximately $1 \times 10^{6}$ sporozoites can be obtained by processing 10 infected mosquitoes harbouring oocysts ranging between $15-40$ per gut (data provided through the courtesy of Dr. S K Puri). 


\section{Standardization of 3-day Primate Screening Model for Causal Prophylactic Activity Against Plasmodium cynomolgi B}

Test system for large-scale screening of antimalarials for causal prophylactic activity against sporozoite induced infections with Plasmodium cynomolgi B has been standardized at CDRI. A dose of $1.78 \mathrm{mg} /$ $\mathrm{kg}$ primaquine (base) $\mathrm{x} 3$ days (day $-1,0$ and +1 ) has been found to be consistently curative.

\section{Radical Curative Screening for Anti-relapse Activity against $P$. cynomolgi B}

Experimental transmission of sporozoite induced $P$. cynomolgi $\mathrm{B}$ infection has been maintained in rhesus monkeys for long by serial cyclic passage, using $A$. stephensi as vector. The radical curative dose of primaquine in this model has been found to be $1 \mathrm{mg}$ (base) $/ \mathrm{kg}$ x 7 day (by oral route) which gives $100 \%$ curative rate. The sensitivity of the relapse stages from 17 different cyclic passages to this drug has remained unaltered. Chloroquine used as companion blood schizontocide with primaquine was curative at $3 \mathrm{mg}$ (base)/ $\mathrm{kg} \mathrm{x} 7$ days. No escalation of primaquine/ chloroquine curative doses was observed during the study.

The protocol reported in this communication would be useful for large-scale screening of new antirelapse compounds which would be potentially useful for radical curative treatment of vivax malaria.

\section{Gametocytocidal/Sporontocidal Screening against $P$. cynomolgi $\mathrm{B}$}

In order to screen new antimalarials for gametocytocidal activity, Plasmodium cynomolgi B infection in rhesus monkey provides an ideal test system since mosquitoes (Anopheles stephensi) can be readily infected with this parasite after feeding on gametocyte carrying monkeys and the data can be quantitated by dissecting mosquito guts on day 8 postfeeding for recording the reduction of mosquito infectivity rate and mean oocyst count on the gut.

\section{Gametocytocidal Test}

Oral primaquine administration at $3.16 \mathrm{mg}$ base $/ \mathrm{kg}$ in a single dose to the gametocyte carrying rhesus monkey is able to completely abolish the oocyst infectivity of a gut as shown by day 8-9 dissections of mosquitoes. Primaquine produces $100 \%$ sterilization of the guts within $24 \mathrm{hrs}$ of drug treatment (Tripathi and Dutta, 1994).

\section{Sporontocidal Test}

In vitro sporontocidal effect of primaquine against $P$. cynomolgi B was studied. The mosquitoes which were infected 3-4 days earlier by feeding them on infected monkeys, were again allowed to feed on drug treated healthy monkey. Our results show that $10 \mathrm{mg}$ and $20 \mathrm{mg}$ base $/ \mathrm{kg}$ of primaquine did not abolish infectivity of mosquitoes and the oocyst count of all the batches fed on drug treated monkey was reasonably high.

\section{Assessment of Methaemoglobinaemia in Beagle Dogs for Met-Hb Toxicity of Primaquine Derivatives}

Beagle dog model has been standardized to evaluate changes in methaemoglobin levels as well as alterations in other haematological parameters (viz. haemoglobin, RBC count, WBC count, differential leucocyte count, mean corpuscular volume) and the liver function tests (viz. SGOT, SGPT, LDH and bilirubin) using primaquine as the reference 8aminoquinoline drug. The results showed that primaquine treatment at $1.0 \mathrm{mg} / \mathrm{kg}$ and $3.0 \mathrm{mg} / \mathrm{kg}$ for 7 days raised methaemoglobin levels by 3.7 and 10.5 folds respectively, over the corresponding day 0 value. No significant alterations in other haematological indices and liver function tests were observed.

\section{Findings}

\section{Antimalarial Drug Discoveries}

\section{Blood Schizontocides}

\section{Arteether $a / b(30: 70)$}

A new blood Schizontocide/Gametocytocide Transmission Blocking Drug

(i) Fast-acting blood schizontocide for $P$. falciparum, P. vivax (Dutta et al. 1987; Patent 1990, 2001, CSIR-CDRI/CIMAP).

(ii) Active against Chloroquine/Mefloquine/Quinine resistant/multidrug resistant complicated 
malarias (P. falciparum/P. vivax).

(iii) Active against uncomplicated/severe complicated malarias.

(iv) Powerful injectible $\alpha / \beta$-arteether containing 150 $\mathrm{mg}$ drug, formulated in double refined, neutralized ground-nut oil for the control of comatose/cerebral malaria cases.

(v) Safe intramuscular injection (3 $\mathrm{x}$ doses), having successfully completed Phase I, II, III, postmarketing (IV) clinical trials.

(vi) $\alpha / \beta$-Arteether exerts strong gametocytocidal (transmission blocking action) against $P$. cynomolgi $\mathrm{B}$ and $P$. falciparum (Fig. 1 shows gametocytocidal action of $\alpha / \beta$-arteether $5 \mathrm{mg} /$ $\mathrm{kg}$ IM dose in monkey).

(vii) $\alpha / \beta$-Arteether is effective against simian malaria P. knowlesi, P. cynomolgi B, P. fragile) and zoonotic $P$. knowlesi (monkey) malaria infections/epidemics in human subjects.

(viii) $\alpha / \beta$-Arteether pharmacokinetics showed that each injection dose is effective beyond $32 \mathrm{hrs}$,
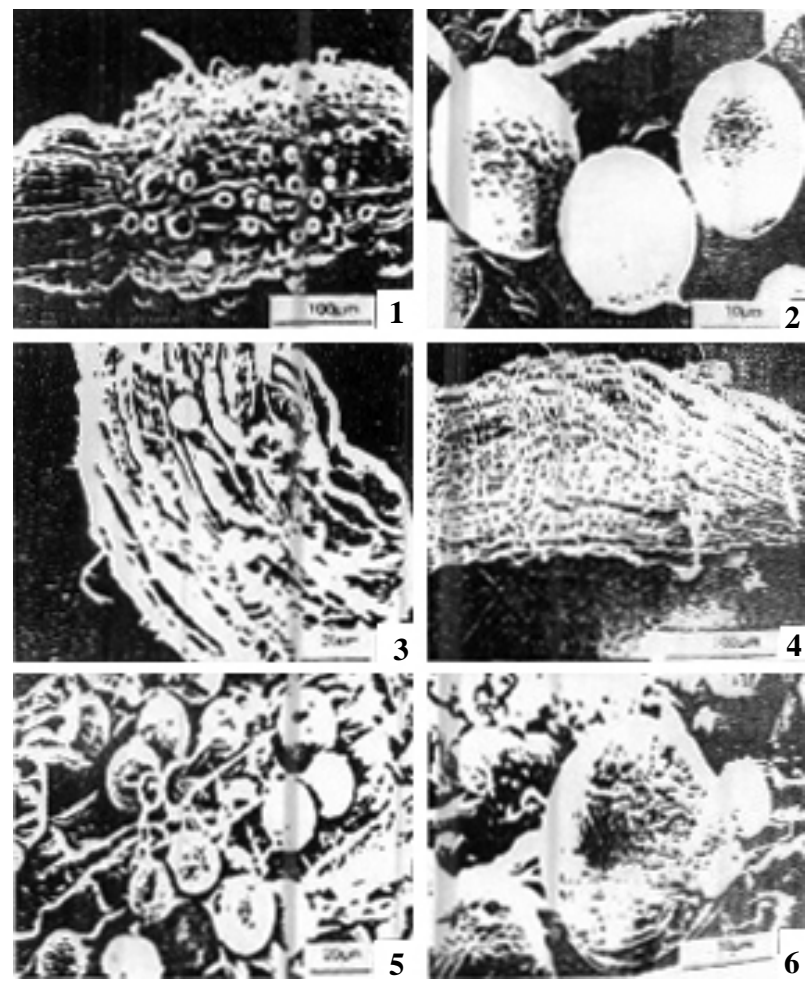

Fig. 1: Gametocytocidal action of $\alpha / \beta$-Arteether (Photo 3 and 4) and antimalarial action of 3 dose (IM injections) extends beyond $120 \mathrm{hrs}$.

(ix) Both $\alpha$ and $\beta$ annomers (30:70) in $\alpha / \beta$-Arteether exert powerful synergistic antimalarial action against MDR malaria and cure highly multidrug resistant $P$. yoelii nigeriensis MDR strain (in standard 4 dose IM treatment schedule in Swiss mice) developed at CDRI.

(x) Discovery of gametocytocidal action of artemisinin (Qinghaosu) was first discovered by Dutta et al. (1989) indicating the transmission blocking activity of artemisinins (Fig. 2 shows gametocytocidal action of $5 \mathrm{mg} / \mathrm{kg}$ IM dose of artemisinin). The $\alpha / \beta$-arteether also exerts gametocytocidal action against simian parasites (Tripathi et al. 1990, 1996) and P. falciparum (Dutta et al. 2001 US Patent).

(xi) National Drug Policy on Malaria - India Directorate of National Vector Borne Disease Control, Ministry of Health and Family Welfare Programme (Government of India, 2010) Arteether injection for severe malaria included in malaria control.
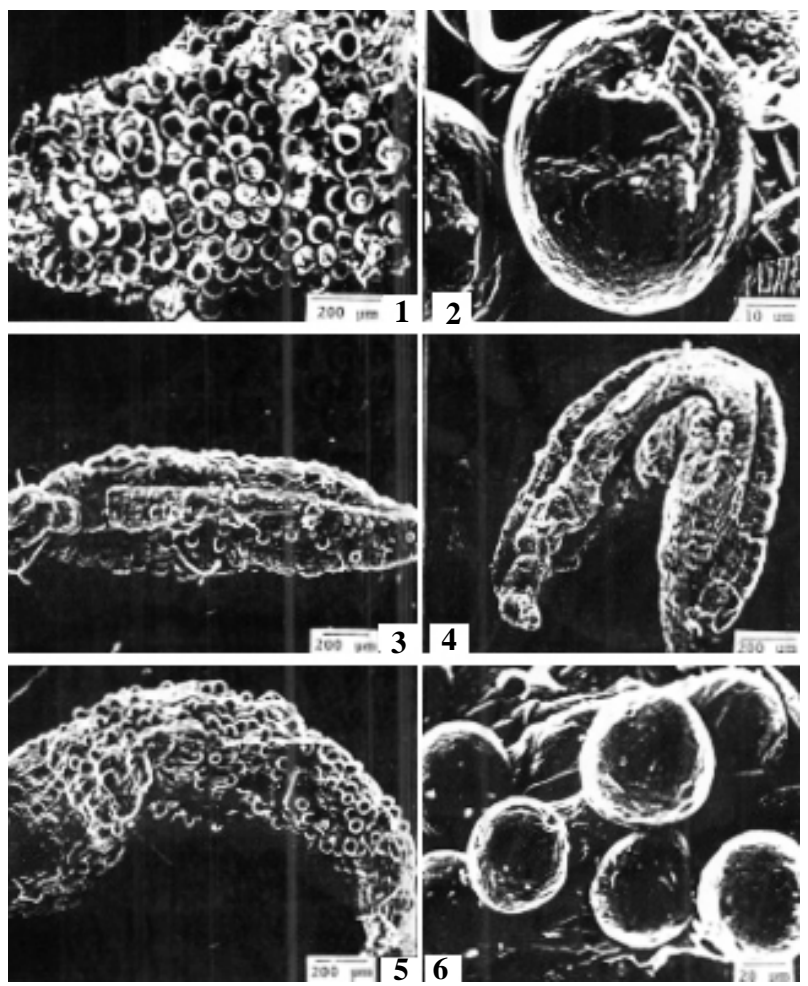

Fig. 2: Gametocytocidal action of artemisinin on the oocyst (Photo 3 and 4) 
(xii) Drug was marketed as E-MAL® in 1997.

(xiii) $P$. yoelii nigeriensis has also been used as primary strain for selection of drug $\alpha / \beta$-Arteether (Dutta et al. 1989), which shows curative action against:

P. knowlesi WI simian malaria (Bajpai et al. 1989).

P. cynomolgi B simian malaria (Dutta et al.1988; Tripathi et al. 1991)

P. fragile (Tripathi et al. 1997)

P. yoeii nigeriensis MDR (Dutta and Tripathi, 2003)

P. falciparum (Dutta et al.1990) and U.S. patent 2001

(xiv) Plasmodium knowlesi is now recognized as fifth human malaria infection (White, 2008). Zoonotic infection from macaque monkeys is spreading to humans in South-East Asia jungles. $\alpha / \beta$ Arteether is effective against this parasite (Bajpai et al. 1989a).

Clinical Studies on $\alpha / \beta$-Arteether for treatment of uncomplicated $P$. falciparum malaria were conducted in India at the following hospitals/centres/ institutes:

1. CSIR-Central Drug Research Institute, Lucknow

2. Malaria Research Centre, New Delhi

3. Lady Hardinge Medical College, New Delhi

4. Jawahar Lal Nehru Hospital, Bhilai

5. Central Reserve Police Force, Base Hospital, Guwahati

6. Regional Malaria Research Centre (ICMR), Dibrugarh, Assam

7. Malaria Research Centre, Sonapur, Assam

8. Malaria Research Centre/Government Medical College, Jabalpur

9. Tata Main Hospital, Jamshedpur

10. Ispat General Hospital, Rourkela

$\alpha / \beta$-Arteether has been marketed internationally for cerebral malarias since 1997.

\section{Criteria for Selection of $\alpha / \beta$-Arteether (30:70)}

The most important criteria for development of $\alpha / \beta$ Arteether was the curative action against primary $P$. yoelii nigeriensis MDR screen, which is highly virulent rodent parasite, producing $100 \%$ mortality in control (untreated mice), and attaining $100 \%$ parasitaemia in 5-7 days. Arteether treated mice (5 $\mathrm{mg} / \mathrm{kg}$ x 4 days, IM) completely cures all mice (Dutta et al. 1989b). Besides, the drug jointly developed by CIMAP and CDRI, is curative blood schizontocide against rodent and several simian malaria strains, and against $P$. falciparum drug resistant cases including cerebral malaria.

\section{Dihydroartemisinin (DHA)}

A fast-acting blood schizontocide, DHA is one of the most active antimalarials amongst the artemisinin derivatives. The compound is active against multidrug resistant malaria by injection, by oral route and also by the rectal route of administration. DHA, jointly developed by CIMAP and CDRI, has been patented in sixteen countries including US and China (Jain, Dutta et al. 1999, 2000). Antimalarial activity of DHA, the most active artemisinin derivative, was discovered at CSIR-CDRI. DHA is very safe gametocytocidal drug capable of stopping malaria transmission.

\section{Combination of Dihydroartemisinin + Piperaquine}

World Health Organization report (2010) has approved DHA-piperaquine oral tablets $(40 \mathrm{mg}+320 \mathrm{mg}$ combination) treatment for 3 days as fifth ACT for the control of uncomplicated falciparum malaria cases. Medicines for Malaria Venture (MMV) has already used this combination in more than a dozen clinical trials against uncomplicated $P$. falciparum (WHO, 2010).

DHA has strong blood schizontocidal action against highly MDR $P$ yoelii nigeriensis (patented 1999/2000). This information regarding DHA antimalarial profile (IM, Oral, Rectal use) (patented by Jain, Dutta et al. 1999, US 6362219 B1) internationally in sixteen countries, has made this molecule as one of the important components of antimalarial control. 
In areas of emerging artemisinin resistant $P$. falciparum, Ashlay et al. (2014) found that 3 days artesunate therapy followed by 3 days DHApiperaquine regimen in Palin area significantly reduced the failure rates in clinical trials.

\section{4. $\alpha / \beta$-Artelinate}

$\alpha / \beta$-Artelinate is a fast acting blood schizontocide for the control of multidrug resistant malarias. This is a water-soluble artemisinin derivative and can be given intravenously for emergency treatment of complicated, comatose/cerebral malaria $P$. falciparum patients as well as a blood schizontocide for drug resistant $P$. vivax infection. The compound is safe with $\mathrm{LD}_{50}$ dose of $670-1000 \mathrm{mg} / \mathrm{kg}$ in mice model. Besides, the $\alpha / \beta$-artelinate shows high gametocytocidal activity and possesses transmissionblocking activity. Both $\alpha$ and $\beta$ annomers of artelinate showed curative activity against Plasmodium knowlesi infection in rhesus monkey, which is a model for cerebral malaria. $\alpha, \beta$ or $\alpha / \beta$-artelinate have been identified as Drug Development Candidates at CDRI/ CIMAP(Tripathi, Dutta and Klayman, 1992; Tripathi, Vishwakarma and Dutta 2008; Vishwakarma et al. 1989, 1992; Tripathi, Puri and Dutta, 1996).

\section{Pyronaridine}

Pyronaridine is one of the most effective blood schizontocide against MDR $P$. yoelii nigeriensis (discovered at CDRI, Dutta et al., 2000; Tripathi et $a l ., 2000)$. The compound is water-soluble and produces $100 \%$ curative effect against MDR infection by both oral route and intramuscular injection. Following oral administration, the aqueous solution of pyronaridine was curative against MDR $P$. yoelii nigeriensis at $15 \mathrm{mg} / \mathrm{kg} \times 7$ days treatment schedule. Pyronaridine showed very high blood schizontocidal action by intramuscular route of drug administration in Swiss mice (20 $\pm 2 \mathrm{~g}$ ) and the IM dose of $2.5-3 \mathrm{mg} /$ $\mathrm{kg} \times 4$ days was $100 \%$ curative against MDR $P$. yoelii nigeriensis (Dutta et al., 2000; Tripathi et al., 2000). A combination of artesunate with pyronaridine has been included in the MMV (2014) Drug Development Portfolio in which pyronaridine has the potential to control MDR malaria. Artesunate is a fast-acting drug, but it may not cure highly MDR $P$. falciparum infection in complicated cases, unless it is given with a longer acting partner like mefloquine (WHO proposed ACT). In view of the author's earlier publications (2000), MMV have incorporated pyronaridine as effective longer-acting drug partner which can control highly MDR infection. MMV (2014) are also developing oral paediatric formulation of artesunate + pyronaridine (ACT) for the malaria in children. Pyronaridine has dual role for its ability to control MDR malaria and a much longer half-life than conventionally used artesunate in WHO ACT formulations.

Besides MMV, Shin Poong Pharmaceuticals has also marketed pyronaridine combination with artesunate (oral formulation) designated (Pyramax ${ }^{\circledR}$ ) for MDR P. falciparum treatment.

\section{Synthetic 1,2,4-Trioxanes/Fenozans}

Among the synthetic endoperoxides the Fenozans compounds 11 and 45 (received through the courtesy of Professor C W Jefford, Switzerland) have been found to be curative against $P$. yoelii nigeriensis MDR screening rodent malaria model. The compound Fenozan 11 is designated as 3,3-spirocyclopentane and Fenozan 45 as 3,3-spirohydropyran. Both Fenozans 11 and 45 formulations in neutral groundnut oil were $100 \%$ curative at $30 \mathrm{mg} / \mathrm{kg}$ x 5 doses (by oral route) administered to mice infected with MDR $P$. yoelii nigeriensis. Both these synthetic trioxanes can be considered for drug development as blood schizonts.

\section{Synthetic Substituted 1,2,4-Trioxanes}

Extensive synthesis and preclinical antimalarial investigation of very promising synthetic trioxanes had been carried out at CDRI by Singh and Puri (2001) and patented (US 6316,493). Extensive in vivo screening had been carried out against MDR $P$. yoelii nigeriensis rodent parasite in Swiss mice. Nearly 10 compounds (25a, 27a, 27b, 27c, 27f, 28a, 31a, 35a1, 41a, 41b) were curative against MDR parasite by IM route. Three compounds (27b, 41a and $41 \mathrm{~b})$ were curative by oral route against $P$. yoelii nigeriensis. Further tests against P. cynomolgi $\mathrm{B}$ in rhesus monkey blood schizontocidal test confirmed activity of 27a, 27b, 41a, 41b which were considered for further studies against $P$. knowlesi in rhesus monkey model. Finally compound 27 a also cured $P$. knowlesi infection (US 6316,493). Two of these compounds $27 \mathrm{a}$ and $41 \mathrm{a}$ were also tested for gametocytocidal 
activity against $P$. cynomolgi $\mathrm{B}$ and $P$. yoelii nigeriensis and their gametocytocidal action was confirmed.

Two fully synthetic 1,2,4-trioxane derivatives are under preclinical development. Compound CDRI 99411 had been identified for drug development. Activity of 99-411 against $P$. yoelii nigeriensis MDR and against $P$. cynomolgi had been confirmed and this was handed over to IPCA Pharmaceuticals for further Phase I evaluation.

Gupta and Srivastava (2014) reported that pharmacokinetic studies with $97 / 78$ showed very rapid metabolism to CDRI 97/63, resulting in low bioavailability of $97 / 78$.

\section{Arterolane Maleate $(O Z 277=R B x 11160)$}

Compound OZ277 (RBx11160), a new fully synthetic peroxide antimalarial (also known as Dispiro 1,2,4Trioxolane antimalarial series) was synthesized and patented by Professor Vennerstrom et al. (2004) in U.S. (Patent Application 20080125411), as a fast acting blood schizontocide. Vennerstrom et al. (2010) had discovered that OZ277 (Arterolane) showed single dose curative activity against $P$. berghei ANKA infection, with a curative dose of $30 \mathrm{mg} / \mathrm{kg}$ in mice. Besides, this compound possesses prophylactic activity against $P$. berghei at $100 \mathrm{mg} / \mathrm{kg}$ single dose (U.S. 20080125411). It is interesting to note that the antimalarial profiles of this 1,2,4-Trioxolane (OZ277) is considered by the authors comparable to that of dihydroartemisinin which had been patented (Jain et al. 1999, 2000, U.S. Patents) as one of the most active artemisinin derivative. Valecha et al. (2010) have successfully carried out Phase II multicentric trials with Arterolane (RBx11160) for acute uncomplicated MDR P. falciparum in Thailand, India and Tanzania. Recently Valecha et al. (2012) have extended the clinical trials with synthetic Trioxolane Arterolane in combination with piperaquine (in Phase III) in Bangkok and India. Arterolane-piperaquine combination is considered safe and effective new drug combination for the control of uncomplicated P. falciparum. It is a promising future addition to antimalarials for malaria eradication.

The combination therapy (ACT) is a deliberate strategy to delay the development of drug resistance. ACTs deliver a two-punch attack on the malaria parasite. By combining two drugs with different mechanisms of action and different time spans of activity, combinations can increase the likelihood that any parasites not killed by one drug will be killed by the second one.

\section{Life Saving Rectal Antimalarial Suppositories}

\section{Artemisinin Suppositories}

Rectal suppositories of artemisinin (Qinghaosu) had been used by large number of workers, including $\mathrm{Li}$ et al. (1985), Li et al.(1994), Arnold (1990), Hien et al. (1991), Hien et al. (1992), Cao et al. (1997), to control critically sick cases of Plasmodium falciparum including cerebral malaria complications. A very high dose of artemisinin had been used ( 2800 $\mathrm{mg}$ drug in $48-56 \mathrm{~h}$ ) to achieve complete parasite clearance in blood smears. This high dose may approach neurotoxicity level together with frequent problems of low cure rates.

\section{Artesunate Suppositories}

Artesunate suppositories given to P. falciparum critical cases required a very high dose (1600 mg in 8 doses over 3 days), but in order to prevent recrudescence of malaria, a second long-acting drug was always prescribed (1250 mg mefloquine to achieve $92 \%$ cure rate (Looareesuwan et al. 1995). Looareesuwan et al. (1995) used $1600 \mathrm{mg}$ artesunate suppository $+1250 \mathrm{mg}$ mefloquine (96\% cure rate), Bhatt et al. (1996) used $1600 \mathrm{mg}$ artesunate +1000 mg mefloquine. In spite of double antimalarial use, there was $13.6 \%$ mortality ( $86.4 \%$ cure rate). Gomez Landires (1996) used $1400 \mathrm{mg}$ artesunate suppository followed by $750 \mathrm{mg}$ mefloquine, Thwe et al. (1996) gave $1200 \mathrm{mg}$ artesunate suppository followed by $1250 \mathrm{mg}$ mefloquine for treatment of severe falciparum malaria. Artemisinin or artesunate or artemether based suppositories are not able to prevent mortality in children, infants and in pregnant women.

\section{3. $\alpha / \beta$-Arteether Suppositories}

$\alpha / \beta$-Arteether suppositories as shown by results in experimental severe MDR malaria model ( $P$. yoelii nigeriensis $\mathrm{MDR}$ ) are very fast acting, and highly efficient in controlling acute infections in mice model and $20 \mathrm{mg} / \mathrm{kg}$ dose x 3 days has shown $100 \%$ suppression of virulent MDR infection, leading to 
survival of treated mice. Suppository containing 50 $\mathrm{mg} / \mathrm{kg} \alpha / \beta$-arteether (x3 days) gives 100 percent survival of mice up to 28 days and no recrudescence of parasitaemia was observed. There is no need to give a second antimalarial e.g. mefloquine as reported with artesunate suppositories.

\section{Dihydroartemisinin (DHA) Suppositories}

DHA suppositories developed by Dutta et al. (1998) in the present study are most active antimalarial amongst the artemisinin derivatives. The conversion of artesunate, arteether, artemether, artelinate etc. to DHA is unique example in pharmacology because all these artemisinin derivatives are metabolized into DHA, which is the most active antimalarial as shown by several investigators. DHA suppositories are considered as life-saving in acute malaria. DHA suppositories can revive comatose cases of malaria and can be used in rural areas where hospital facilities are not available. DHA requires much lower dose, which is safe. DHA formulations are known to exhibit gametocytocidal activity and give additional benefit to interrupt malaria transmission. DHA suppositories can save lives in malaria endemic countries (Patent 2000 U.S.).

\section{Radical Curative/Anti-Relapse Drugs}

\section{Bulaquine (Elubaquine, CDRI 80/53)}

Anti-relapse activity of this compound has been published by Dutta et al. 1989 and Puri et al. 1989. This is the safest anti-relapse (radical curative) compound effective against relapsing Plasmodium vivax malaria. The compound also shows the gametocytocidal action against Plasmodium falciparum. The compound Bulaquine is a candidate drug which has passed through Phase I, II and III clinical trials for anti-relapse efficacy. Bulaquine has been cleared as safe drug in regulatory toxicology following administration of the drug for three months (Sethi et al., 1993, 1988). This compound is the drug of choice to replace Primaquine (as anti-relapse as well as gametocytocidal drug). This produces three to four fold lower level of methaemoglobinaemia as compared to Primaquine as shown by methaemoglobin estimations in the human subjects.

The code name of Compound 80/53 CDRI has been revised by World Health Organization to bulaquine (=elubaquine) according to WHO Drug Information Vol. 13, No. 4, 1999, p. 268 (proposed INN List 82), and CDRI 80/53 compound is named as dihydro-3-[1-[[4-[[6-methoxy-8-quinolyl]amino] pentyl]amino]ethylidene]-2(3H)-furanone.

\section{Phase II/III Clinical Trials with CDRI 80/} 53: Phase II/III clinical trials with CDRI $80 / 53$ had been undertaken at Malaria Research Centre, Delhi. The results of clinical trials on the anti-relapse efficacy of primaquine ( $15 \mathrm{mg}$ daily $\mathrm{x} 5$ days) was compared with CDRI 80/53 (25 mg daily $x 5$ days) using standard 5 day regimen for treatment of $P$. vivax cases (Table 1). Short-term follow-up during non-transmission period (mid-November to March) showed relapse rate of $4.9 \%$ for CDRI $80 / 53$ and $3.0 \%$ for primaquine in comparison to placebo (chloroquine) which gave $10.6 \%$ relapse rate. This analysis showed that antirelapse efficacy of primaquine and CDRI 80/53 was comparable. Long-term follow-up studies up to one year showed a relapse rate of $26.8 \%$ after primaquine therapy, as compared to $29.6 \%$ after treatment with

Table 1: Instruction manual for 6 days treatment of malaria caused by Plasmodium vivax (relapsing malaria) using Aablaquine (combination of chloroquine for three days and Bulaquine for 5 days) to clear hypnozoite from the liver

\begin{tabular}{|c|c|c|c|c|c|c|}
\hline & Day 1 & Day 2 & Day 3 & Day 4 & Day 5 & Day 6 \\
\hline \multirow[t]{2}{*}{ Chloroquine tablet } & $\begin{array}{l}\text { Start with } 2 \text { tablets } \\
\quad(300 \mathrm{mg} \times 2)\end{array}$ & 1 tablet $300 \mathrm{mg}$ & 1 tablet $300 \mathrm{mg}$ & $\mathrm{X}$ & $\mathrm{X}$ & $\mathrm{X}$ \\
\hline & $\begin{array}{l}1 \text { tablet after } 6 \text { hours } \\
(300 \mathrm{mg} \times 1)\end{array}$ & + & + & & & \\
\hline $\begin{array}{l}\text { Capsule of compound of } \\
\text { formula (I) (Bulaquine) }\end{array}$ & $\begin{array}{c}X \\
25 \mathrm{mg}\end{array}$ & $\begin{array}{l}1 \text { capsule } \\
25 \mathrm{mg}\end{array}$ & $\begin{array}{l}1 \text { capsule } \\
25 \mathrm{mg}\end{array}$ & $\begin{array}{l}1 \text { capsule } \\
25 \mathrm{mg}\end{array}$ & $\begin{array}{l}1 \text { capsule } \\
25 \mathrm{mg}\end{array}$ & 1 capsule \\
\hline
\end{tabular}

Aablaquin oral anti-relapse regimen for P. vivax comprising of Chloroquine (x 3 days) and Bulaquine (x 5 days); CDRI Patent. 501/ MUM/2000 Grant 31.05.2000 IN. Mumbai 
CDRI 80/53 (Valecha et al. 2001). The relapse rate of untreated (placebo) control $P$. vivax was around $40.1 \%$ in Delhi area. In the long-term relapse data, the cases showing true relapse and re-infections from endemic area cannot be distinguished. The drug CDRI 80/53 (Elubaquine=Bulaquine) has been marketed since 2000 in combination with chloroquine as Aablaquine - a safe radical curative (anti-relapse) kit for treatment of $P$. vivax cases.

Krudsood et al. (2006) evaluated the antirelapse activity of Elubaquine (compound CDRI 80/ 53) against $141 P$. vivax malaria cases. Both Elubaquine and Primaquine were evaluated in two batches of patients following treatment with standard Chloroquine, $30 \mathrm{mg} / \mathrm{kg}$ given over 3 days. Group A n $=71$ patients were administered $30 \mathrm{mg}$ Primaquine once daily for 7 days and Group B $n=70$ patients were administered $25 \mathrm{mg}$ Elubaquine (compound 80/ 53) (Bulaquine) once daily for 7 days. According to their findings, all patients cleared $P$. vivax blood stage parasites within 7 days after Chloroquine treatment. One of the 71 patients treated with Primaquine relapsed on day 26 while none of the 70 patients treated with Elubaquine (Bulaquine) showed any relapse. Fever clearance time in group A was 18.65 hours (range 4-70 hours) and in group B 22.74 hours (range 4-90 hours). Parasite clearance (mean time) was 43.68 hours in group A and 44 hours in group B. Serious adverse effects (cyanosis, abdominal cramps, hypertension, arrhythmias, CNS symptoms etc.) were not observed in both group A or B. Both Primaquine and Elubaquine were well-tolerated in $P$. vivax cases. The authors also observed that 4 patients with G6PD deficiency who were treated with Primaquine had clinically significant fall in hematocrit, whereas 3 patients with G6PD deficiency treated with Elubaquine did not show significant fall in hematocrit. The authors finally concluded that Elubaquine (Bulaquine) (Group $\mathrm{B}, \mathrm{n}=3$ ) treated patients with G6PD deficiency did not show clinically significant hemolysis (Krudsood et al., 2006). Besides the anti-relapse activity, bulaquine (Elubaquine) was evaluated for gametocytocidal activity by Gogtay et al. (2006) and it was reported that clearance of $P$. falciparum was better with Bulaquine than with Primaquine. The dose for gametocytocide was close to $75 \mathrm{mg}$ single dose in human trials.

\section{Tafenoquine (WR 238605)}

This compound has been developed jointly with Walter Reed Army Research Institute, Washington, DC. The compound shows exceptional anti-relapse, gametocytocidal action and represents another molecule to substitute Primaquine. Primate malaria studies conducted at CDRI showed that the compound is seven times more effective at $\mathrm{ED}_{50}$ level compared to Primaquine (Milhous et al. 1988).

Douglas et al. (2012) had reported that Tafenoquine and Bulaquine (Elubaquine/CDRI 80/53) were both considered to be hypnozoitocidal drugs. The author wishes to record that judging on the basis of methaemoglobin toxicity, the CDRI compound 80/ 53 (Bulaquine/Elubaquine) is the safest anti-relapse drug discovered till date (October, 2015) as the compound was found safe in three months sub-acute regulatory toxicity as far as its methaemoglobin safety level in clinical trials was concerned.

\section{Causal Prophylaxis}

Causal Prophylaxis Activity of Two New Compounds (Bulaquine/Elubaquine and Tafenoquine)

1. Bulaquine (Elubaquine) (CDRI compound 80/ 53) (Dihydro-3-[1-[[4-[(6-methoxy-8-quinolyl)amino] pentyl]amino]ethylidene]-2(3H)-furanone). This 8 aminoquinoline derivative synthesized at CDRI 80/ 53 , has already undergone evaluation for radical curative activity against sporozoite induced P.cynomolgi B in rhesus monkey as well as for gametocytocidal activity against $P . c y n o m o l g i \mathrm{~B}$. The compound has undergone detailed drug development, and safety Phase I studies in human subject and also successfully completed Phase II/III evaluation for radical curative activity against $P$. vivax at Malaria Research Centre (ICMR), New Delhi (Valecha et al. 2001).

Causal prophylactic activity of Bulaquine (CDRI 80/53) against $P$. cynomolgi $\mathrm{B}$ in rhesus monkey is: $3.16 \mathrm{mg} / \mathrm{kg} \times 3$ doses is curative and single dose of $80 / 53$ at $10 \mathrm{mg} / \mathrm{kg}$ on day 0 was also curative in rhesus monkey. Only experimental studies have been undertaken and the drug is safe. 
2. Tafenoquine (Compound WR 238605) (WRAIRCDRI Collaboration)

The causal prophylactic activity of WR 238605 was evaluated in 22 rhesus monkeys at doses in the range 0.03-1 mg (base) $/ \mathrm{kg}$ (Table 2) using 3 day treatment schedule. All the four monkeys treated at $0.03 \mathrm{mg} / \mathrm{kg}$ dose became patent on day 8. Likewise, 6 out of 7 monkeys treated at $0.1 \mathrm{mg} / \mathrm{kg}$ also developed patency between days 8 and 17, while one monkey was protected. Nine out of 9 monkeys at $0.316 \mathrm{mg} / \mathrm{kg}$ and $2 / 2$ monkeys at $1 \mathrm{mg} / \mathrm{kg}$ were protected.

Table 2: Causal prophylactic activity of compound WR 238605 against sporozoite induced $P$. cynomolg $i$ B infection in rhesus monkeys

\begin{tabular}{|c|c|c|c|c|}
\hline \multirow{2}{*}{$\begin{array}{l}\text { Daily dose } \\
\mathrm{mg}(\text { base }) / \mathrm{kg}\end{array}$} & \multirow{2}{*}{$\begin{array}{c}\text { Total } \\
\text { course dose } \\
\mathrm{mg}(\text { base }) / \mathrm{kg}\end{array}$} & \multirow{2}{*}{$\begin{array}{l}\text { No. of } \\
\text { monkeys } \\
\text { treated }\end{array}$} & \multicolumn{2}{|c|}{ Response to treatment } \\
\hline & & & $\begin{array}{l}\text { No. } \\
\text { cured }\end{array}$ & $\begin{array}{c}\text { No. not cured } \\
\text { (day of } \\
\text { patency) }\end{array}$ \\
\hline 0.03 & 0.09 & 4 & 0 & $4(8,8,8,8)$ \\
\hline 0.10 & 0.30 & 3 & 0 & $3(8,8,8)$ \\
\hline 0.10 & 0.30 & 4 & 1 & $3(8,8,8)$ \\
\hline 0.316 & 0.95 & 3 & 3 & 0 \\
\hline 0.316 & 0.95 & 3 & 3 & 0 \\
\hline 0.316 & 0.95 & 3 & 3 & 0 \\
\hline 1.00 & 3.00 & 2 & 2 & 0 \\
\hline \multicolumn{5}{|c|}{ Reference drug Primaquine } \\
\hline 1.78 & 5.34 & 4 & 4 & 0 \\
\hline \multicolumn{5}{|c|}{ Vehicle control } \\
\hline- & - & 4 & 0 & $4(8,8,8,9)$ \\
\hline
\end{tabular}

\section{Antimalarial Drug Discovery Under Indian System of Medicine (Ayurvedic)}

\section{Ayush-64}

Effect of AYUSH-64 in the treatment of Malaria has been extensively studied by the Indian Central Council for Research in Ayurveda and Siddha.

Ayush-64 is a combination of four plants namely Alstonia scholaris (aqueous extract of bark-1 part), Picrorhiza kurroa Royle (aqueous extract of rhizome-1 part), Swertia chirata (aqueous extract of whole plant-1 part) and Caesalpinia crista Linn (fine powder of seed pulp-3 parts).
The drug was patented by the Central Council of Ayurveda and Siddha and to confirm the efficacy in well designed scientific trial, open prospective, noncrossover, randomized clinical trial was conducted in P. vivax malaria patients at the Malaria Research Centre in collaboration with National Anti-Malaria Programme (Valecha et al., 2000). Results showed that with Ayush-64 cure rate on Day 28 was $48.9 \%$ at a dose of $1 \mathrm{~g}$ three times a day for 5-7 days as against $100 \%$ with chloroquine $1500 \mathrm{mg}$ over three days.

According to WHO and Health Ministry reports that over $50 \%$ of the total malaria cases in India are triggered by Plasmodium vivax. This increase in vivax infection is a very serious public health of which only Chloroquine + Primaquine standard regimen needs to be used. The National Vector Borne Disease Control Programme (NVBDCP) has provided the standard vivax control regimen (The National drug policy for malaria, 2013) which must be followed to bring this situation under control. Radical curative/anti-relapse drugs recently developed by the CDRI (Bulaquine/ Elubaquine and Tafenoquine) should be introduced together with standard Chloroquine regimen. It is strongly recommended that Ayush-64 should not be introduced because of its low order of activity (48.9\%) against $P$. vivax as reported by Valecha et al. (2000). Further, it may also be recorded that Ayush-64 has no action against multidrug resistant Plasmodium falciparum which can produce high mortality if not radically cured.

\section{A novel Curcumin and Artemisinin Combination Therapy for Cerebral Malaria}

Padmanaban and his colleagues (Reddy et al., 2005) at the Indian Institute of Science, Bangalore, have, following the use of turmeric by the Indian population for centuries because of its anti-inflammatory/ immunomodulatory action suggested introduction of curcumin (isolated from the roots of Curcuma longa, (Turmeric) for malaria control. Reddy et al. (2005) successfully in established the in vitro antimalarial action of curcumin against cultured chloroquine resistant Plasmodium falciparum (IC50, approximately 5 microM). Besides, the in vivo action of curcumin (oral treatment) reduced blood parasitaemia of $P$. berghei infected mice by $80-90 \%$ (Reddy et al., 2005). 
Further studies by Nand Kumar et al. (2006) reported that in vitro interaction between curcumin and artemisinin against $P$. falciparum was additive interaction. These in vitro studies were followed by in vivo evaluation of single IM doses $(500 \mu \mathrm{g}, 750 \mu \mathrm{g}$, $1.5 \mathrm{mg}$ ). In the in vivo study, 3 oral doses of curcumin $(5 \mathrm{mg}$ ) following a single injection of $\alpha / \beta$-Arteether ( $500 \mu \mathrm{g}, 750 \mu \mathrm{g}, 1.5 \mathrm{mg}$ doses) to P. berghei infected mice were able to prevent recrudescence only at higher $\alpha / \beta$-Arteether (single dose $750 \mu \mathrm{g}$ and $1.5 \mathrm{mg}$ ) monotherapy, which ensured $100 \%$ survival of the mice.

Padmanaban and his colleagues have obtained leads to suggest that combination therapy with curcumin and $\alpha / \beta$-Arteether could be successfully exploited to prevent recrudescence of Plasmodium berghei-infected mice through immunomodulatory action (Vathsala et al., 2012). In a recent publication (Dende et al., 2015) with experimental cerebral malaria (ECM) in mice infected with $P$. berghei ANKA (cerebral malaria model), the curcumin alone treatment was able to reverse all the parameters governing inflammatory responses, parasitized RBC sequestration into the brain and blood brain barrier (BBB) breakdown, although the animals died of anaemia due to rising blood parasitaemia. They further observed that combination of Arteether-curcumin therapy provided complete cure even after the onset of symptoms. Professor Padmanaban's group (2015) finally concluded that arteether-curcumin combined therapy appeared to be a promising therapeutic lead for preventing human cerebral malaria.

\section{Discussion}

Medicines for Malaria Venture, Switzerland (MMV), a non-profit European Agency, has done extensive studies in collaboration with International Agencies and Institutions to develop new candidate drugs for clinical trials for control of multidrug resistant malaria as well as for anti-relapse activity. They have made extensive studies on the identification of new entities, which could be further exploited for new drugs development.

Although, there is no formal agreement between Council of Scientific and Industrial Research (CSIR), New Delhi (CDRI/CIMAP Patent Assignee), and MMV to cooperate/collaborate in promoting "New
Antimalarial Drug Development Internationally", it is encouraging to report that at least five antimalarials patented or published by CSIR-CDRI/CIMAP, Lucknow (Azithromycine, 2005), Tafenoquine (WR 236805) (1988, 1994, 2003), Pyronaridine (2000a,b), Dihydroartemisinin (DHA) (Patent 1999/2000) and technology transfer for Artemether (Process 2000) have been incorporated in the MMV Drug Discovery Candidates for Clinical Development (2014). It is heartening to note that clinical trials with some of these drugs have been carried out on Indian malaria infected clinical cases also to ensure efficacy against malaria infected $P$. falciparum cases in India. All the five drug candidates have shown curative efficacy against highly resistant MDR strain of $P$. yoelii nigeriensis developed by the Author. Discovery and development of tafenoquine (WR 238605), a broad spectrum antimalarial (synthesized by Walter Reed), was tested at CDRI under WRAIR (Walter Reed Army Institute of Research)-CSIR-CDRI collaboration and was published in 1988, 1994, 2003 and 2005 jointly by WRAIR-CDRI groups. This compound (WR 238605=Tafenoquine) underwent extensive studies at CDRI for its blood schizontocidal activity, as antirelapse (hypnozoiticidal against dormant liver stages), as causal prophylaxis drug, and as gametocytocidal drug against $P$. cynomolgi $\mathrm{B}$ infection in rhesus monkey model. The drug has moderate toxicity like methaemoglobin toxicity of Primaquine, but it can be administered at considerably high doses of the drug, which are considered safe. International investigators are continuing clinical trials in US Defense Department as well as Australia. US Agency, WRAIR had also agreed that tafenoquine (WR 238605) could be developed by CDRI for use in the Indian Malaria Control but WRAIR would hold US and International Rights, to develop this broad-spectrum antimalarial, initially developed as long-acting antimalarial for use by the US. In the 2014 MMV Report, tafenoquine (WR 238605) has also been included for joint collaboration with Glaxo-Smith-Kline. The first report on the anti-relapse activity of WR 238605 (Tafenoquine) jointly co-authored by WRAIR and CDRI collaborative programme, was published by Milhous et al. (1988). According to the above report, the anti-relapse activity of Tafenoquine calculated on the basis of $\mathrm{CD}_{50}$ dose was 7.4 times more active as anti-relapse agent when compared to Primaquine in rhesus monkey P.cynomolgi B radical curative test. 
It was further reported that the new anti-relapse drug 8-aminoquinoline WR 238605, with its reduced toxicity, good oral bioavailability and much longer halflife, was an excellent potential candidate to replace Primaquine.

MMV Report (2010) is focused on the Theme: "Meeting the Challenge of Artemisinin Resistance". Tim (2010) reported that they had 11 new chemical entities in development and 23 across the entire portfolio. The key is to find new molecules that will kill the parasite as quickly as artemisinin.

According to the MMV report, more than five million compounds were screened successfully for antimalarial activity and over 20,000 compounds showed significant activity against the malaria parasite.

More than thirty two research agendas for malaria control and global eradication (Appendix-I) have been recently published with major objectives to achieve the malaria eradication by promoting antimalarial drug development and drug research, antimalarial vaccines, application of safe insecticides, mosquito nets, mosquito control technologies involving new insecticides development, biocides for vector control, indigenous technologies for repelling mosquitoes. The World Health Organization and international teams of committed malaria research scientists have pooled their resources to protect African Children who suffer the most due to malaria epidemics.

"A Research Agenda for Malaria Eradication: Drugs", a comprehensive report was brought out by the MalERA Consultative Group on Drugs (2011). And the major thinking of the Group of International Participants was that "Malaria Eradication is not possible with existing tools" which include: Artemisinin-based combination treatment (ACTs), long-acting insecticide-treated nets, and insecticide spraying. According to the MalERA Drugs Consultative Group, "the complete malaria eradication will not be accomplished within most of our lifetimes and that new tools, including new antimalarial drugs developed specifically for elimination indications". These include (1) transmission blocking safe drugs to kill/sterilize immature and mature gametocytes of $P$. falciparum, (2) successful treatment of MDR complicated $P$. falciparum infection/fast-acting blood schizontocides for comatose malaria cases (both $P$. falciparum/P. vivax), (3) elimination of relapsing liver stages (hypnozoites) of $P$. vivax/P. ovale, i.e. safer anti-relapse drugs for radical cure of $P$. vivax (to replace Primaquine), (4) develop safe causal prophylactic agents and (5) new ACTs for treatment of uncomplicated $P$. falciparum infection e.g. DHApiperaquine combination approved by WHO (2010).

Commendable efforts have been made by committed scientists of the MMV group (Anthony et al. 2012) who have tried to report updates on the status of global pipeline of new antimalarials. In the past three years, four new medicines were prequalified by World Health Organization as fixed dose, artemisinin-combination therapy (ACTs) to protect against emerging artemisinin resistance. These included: (1) ACT comprising of ArtemetherLumefantrine (Coartem Tablets and Coartem Dispersable from Novartis), (2) ArtesunateAmodiaquine (Coarsucam ${ }^{\mathrm{TM}}$ /Artesunate Amodiaquine) (Winthrop ${ }^{\mathrm{R}}$, Sanofi), (3) PyronaridineArtesunate $\left(\right.$ Pyramax $\left.^{\mathrm{R}}\right) \quad$ (Shin Poong Pharmaceuticals) and (4) Mefloquine-Artesunate (Cipla/DNDi) (prequalified by WHO). Besides, four other types of ACTs are prescribed for uncomplicated malaria (including (a) Dihydroartemisinin (DHA) Piperaquine (Eurartesim ${ }^{\mathrm{R}}$-Sigma-Tau) and DuoCotecxin $^{\mathrm{R}}$ (Holley-Cotec), (b) PyronaridineArtesunate, (c) Artesunate-Mefloquine (ASMQ) (Cephalon/Mepha) and (d) Artemisinin-Naphthoquine (ARCO, Kunming, China) which is available as one day treatment.

Burrows et al. (2013) have put forward the malaria eradication agenda with focus to design next generation of antimalarials to target different stages of malaria parasite. According to MMV concept for malaria control, (1) new fast-acting medicines for control of emerging artemisinin resistant malaria, (2) new medicines to reduce transmission of malaria (through their use to eradicate early and late stages of gametocytocides, (3) medicines for prevention of relapses due to dormant hypnozoites stage of $P$. vivax/ $P$. ovale, to eliminate relapsing stages of malaria, (4) medicines for achieving radical cure, a single exposure radical cure and prophylaxis therapy (against 
sporozoite infection), has been proposed together with new drugs for elimination of asymptomatic sexual stages (interruption of transmission by the gametocytes). Flannery, et al. (2013) discussed the problem of antimalarial drug discovery directed to the ultimate objective of complete elimination of global malaria. Flannery, et al. (2013) also admitted that the current antimalarial drugs were inadequate to achieve complete elimination of malaria. These investigators report that artemisinins are fast-acting and very potent against blood stage parasites as schizontocides, besides showing activity against early sexual stages of the parasite, and they also realized the importance of blocking transmission of malaria.

The author agrees with the conclusions of Flannery, et al. (2013) that artemisinins can act as very effective gametocytocide to block transmission of malaria (Dutta et al., 1989; Tripathi et al., 1990 and 1996; Dutta and Tripathi, 2003; Dutta et al., 2000; Jain, Dutta et al., 1999, 2000; Dutta et al., 2001).

It needs to be emphasized that CDRI compound 80/53 (named Bulaquine=Elubaquine by WHO, 2000) was marketed as Aablaquin (2000) which is 3-4 times safer than Primaquine, and is a potential 8Aminoquinoline which can replace Primaquine as radical curative/anti-relapse drug. Bulaquine eradicates hypnozoite of $P$. vivax at $25 \mathrm{mg} / \mathrm{kg}$ daily dose administered for 5 to 7 days. The drug shows much better safety margin compared to Primaquine (Dutta et al. 1989; Dutta et al., 1998; Puri et al., 1989; Dutta and Puri, 2003). Besides, Tafenoquine (WR 236805) (another 8-Aminoquinoline) has been developed up to pre-clinical stage by CDRI in collaboration with WRAIR, Washington DC, (Milhous et al. 1988; Puri et al., 1994; Puri and Dutta, 2003; Dutta and Puri, 2003).

Extensive chemotherapeutic investigations at CSIR-CDRI have already made major headway in tackling some of the listed obstacles in New Drug Discovery Programmes. They would also provide many new chemotherapeutic agents to tackle some of the bottlenecks to initiate programme for malaria eradication in collaboration with National Antimalaria Programme of Government of India and International Malaria Control Agencies/WHO/US Government programmes/WRAIR. The leads developed at CDRI to tackle and support eradication plans will be available to all International Agencies to progress towards global MalERAAgenda.

\section{WHO-Brief Report on Antimalarial Drug Development at CDRI}

\section{Success Stories in Malarial Control from the SEA Region}

WHO (2012) also documents the progress in antimalarial research leading to following drug developments in India.

(i) $\boldsymbol{\alpha} / \boldsymbol{\beta}$-Arteether (30:70 ratio) - A racemic mixture of ethyl derivative of Artemisinin developed by the Central Drug Research Institute and CIMAP, Lucknow. Multicentric trials for uncomplicated and complicated $P$ falciparum in over 500 patients have shown a recrudescence rate of $8 \%$. The injectable formulation ( $150 \mathrm{mg} / \mathrm{ampoule}$ ) is given IM for 3 days. The drug was marketed in India since 1997 by Themis Chemicals, Mumbai. $\alpha / \beta$-Arteether has been introduced as fast acting blood schizontocide in the treatment of severe/ multidrug resistant $P$. falciparum (This drug was first published in 1987-1988 as fast-acting blood schizontocide by author (Dutta et al., 1987, 1988) and also patented by CSIR-CDRI and CIMAP in 1990 (Vishwakarma R A, Thakur R S, Dutta G P and Bajpai R; Application No. 1070/DEL/ 90, No. 173947).

(ii) Azithromycin (oral) - A macrolide antibiotic has shown delayed blood schizontocidal activity against multidrug resistant $P$. yoelii nigeriensis infection in experimental murine malaria (see Tripathi et al. 2005). Clinical trials had been undertaken by Malaria Research Centre (ICMR), New Delhi.

(iii) Bulaquine - A new anti-relapse (CDRI-80/53) designated by WHO (2000) as Elubaquine, was first published in 1989 (Dutta et al. 1989). This new 8-aminoquinoline is a safer anti-relapse antimalarial. The drug has successfully completed phase I, II, III and IV clinical trials and was marketed in India in year 2000. It was granted US Patent 7183291 (Feb. 27, 2007), EP 1055437 on $13^{\text {th }}$ Oct. 2004; Mumbai 501/MUM/ May 5, 2000 (Last update 9 9 $^{\text {th }}$ Jan. 2007 WHO, SEA Regional Report). 


\section{WHO-Global Malaria Programme $\left(21^{\text {st }}\right.$ May, 2014)}

Emergence and spread of artemisinin resistance calls for intensified efforts to withdraw oral artemisininbased monotherapy from the market. According to the last status report on artemisinin resistance, foci of artemisinin resistance have been identified in five countries in the Greater Mekong sub-region, and resistance is suspected in two countries and one territory in South America. WHO have strongly recommended the pharmaceutical companies not to sale single artemisinin derivatives and they have also recommended that the artemisinins should be administered along with a second long acting antimalarial drug. They have proposed the following ACTs (artemisinin long acting drug combinations) (1) Artemisinin/Lumefantrine, (2) Artesunate/ Amodiaquine, (3) Artesunate/Mefloquine, (4) Artesunate/Sulfadoxin-pyrimethamine and (5) Dihydroartemisinin (DHA)/Piperaquine.

In a very exhaustive study on "Spread of Artemisinin Resistance in Plasmodium falciparum Malaria" in South-East Asia, Ashley et al. (2014) have reported that the following additional artemisinin combinations with above mentioned ACTs could provide valuable treatment schedule for control of expanding artemisinin resistance. According to their findings, a six-day treatment should be introduced in place of standard three-day ACTs treatment. The investigators could obtain $100 \%$ cure rates with the following additional drug regimens: Artesunate $2 \mathrm{mg} /$ $\mathrm{kg}+$ DHA- piperaquine, Artesunate $4 \mathrm{mg} / \mathrm{kg}$ + DHApiperaquine (Vietnam), Artesunate $4 \mathrm{mg} / \mathrm{kg}+$ Artemether-Lumefantrine, Artesunate $2 \mathrm{mg} / \mathrm{kg}+$ Artemether-Lumefantrine (Laos), Artesunate $4 \mathrm{mg}$ / $\mathrm{kg}+$ Artemether-Lumefantrine, Artesunate $2 \mathrm{mg} / \mathrm{kg}$ + Artemether-Lumefantrine (Myanmar) and finally Artesunate $4 \mathrm{mg} / \mathrm{kg}$ + Artemether-Lumefantrine (Democratic Republic of Congo). The authors have strongly recommended that radical measures will be necessary in South-East Asia to prevent resistance to artemisinins and their partner drugs from spreading to the Indian subcontinent and further to Africa. The author wishes to record that the International Scientific Group would at some time explore the potential of $\alpha /$ $\beta$-Arteether (30:70) developed in India, in order to monitor the efficacy of this drug in three to five days schedule (intramuscular $150 \mathrm{mg}$ dose) to assess its potential to control the expanding artemisinins resistance. This is the drug of choice for control of multidrug resistance and cerebral malaria treatment in India.

It may also be mentioned that the dihydroartemisinin has been reported to be most active out of the artemisinin derivatives and this molecule has been patented (1999-2000) by CDRI/CIMAP in Sixteen Countries. WHO have recognized dihydroartemisinin + Piperaquine as a drug of choice for treatment of uncomplicated Plasmodium falciparum as well as $P$. vivax blood stage infections.

\section{World Health Organization: Global Technical Strategy for Malaria 2016-2030}

Dr. Margaret Chan, Director General, WHO (WHO 2015) highlights the urgent need to increase investments across all interventions - including preventive measures, diagnostic testing, treatment and disease surveillance - as well as in harnessing innovation and expanding research. WHO Member States have endorsed the bold vision of a world free of malaria, and set the ambitious new target of reducing the global malaria burden by $90 \%$ by 2030 .

\section{Acknowledgements}

This Status Report on “Antimalarial Drug Discovery in India" has been sponsored by the Indian National Science Academy. I am indebted to Professor Raghavendra Gadagkar, FNA, President, INSA and Professor Krishan Lal, FNA, Past President, INSA, for their guidance and financial support of INSA in bringing out this report. Special thanks are due to Professor S C Lakhotia, FNA, Vice President, INSA Publications, for valuable help and discussions in bringing out this publication. Special thanks are due to Professor Madhu Dikshit, FNA (Director, CSIRCDRI) and Professor A K Tripathi, FNA (Director, CSIR-CIMAP) for their institutional support to antimalarial drug development in India. I wish to express my gratitude to Dr. S K Puri (Ex-Director), Dr. Renu Tripathi (Principal Scientist, Parasitology Division) and late Dr. V C Pandey (Biochemist), for their valuable help in experimental studies. The institutional facilities provided by Dr. P K Seth, CEO, Biotech Park is gratefully acknowledged. I wish to record my thanks to Dr. Geoffrey M Jeffery, Sc D, 
MPH, John Hopkins (my mentor) for introducing me to human malaria chemotherapy (1962-63) in neurosyphilitic patients at Columbia, S C, USA. I express my deep appreciation to my wife Sudesh, and Dr. Sheetij Dutta and Dr. Mala Dutta for their valuable support in completion of this project document.

\section{References}

Afonso A, Hunt P, Cheesman S, Alues A C, Cunha C V, do Rosàrio V and Cravo P (2006) Malaria parasites can develop stable resistance to artemisinin but lack mutations in candidate genes atp6 (encoding the sarcoplasmic and endoplasmic reticulum $\mathrm{Ca}_{2}{ }^{+}$-ATPase), tctp, mdr1, and cg10 Antimicrob Agents Chemother 50 480-489

Anothony M P, Burrows J N, Dupac C S, Moehrie Joerg J and Wells Timathy N C (2012) The global pipeline of new medicines for the control and elimination of malaria Malar J11 316

Arnold K, Hien T T, Chin N T, Phu N H and Mai P P (1990) A randomized comparative study of artemisinin (qinghasou) suppositories and oral quinine in acute falciparum malaria Trans R Soc Trop Med Hyg 84 499-502

Ashley F A, Dhorda M, Fairhust R M, Amaratunga C, Lim P, Suon S, Sreng S, Anderson J M, Mao S, Sam B, Sopha C, Chuor C M, Nguon C, Sovannaroth S, Pukrittayakamee S, Jittamala P, Chotivanich K, Chutasmit K, Suchatsoonthron C, Runcharoen R, Hien T T, Thuy-Nhien N T, Thanh N V, Phu N H, Htut Y, Han K T, Aye K H, Mokuolu O A, Olaosebikan R R, Folaranmi O O, Mayxy M, Khanthavong M, Hongvanthong B, Newton P N, Onyamboko M A, Fanello C I, Tshefu A K, Mishra N, Valecha N, Phyo A P, Nosten F, Yi P, Tripura R, Borrmann S, Bashraheil M, Peshu J, Faiz M A, Ghose A, Hossain M A, Samad R, Rahman M R, Hasan M M, Islam A, Miotto O, Rmato R, MacInnis B, Stalker J, Kwiatkowski D P, Bozdech Z, Jeeyapant A, Cheah PY, Sakulthaew T, Chalk J, Intharabut B, Silamut K, Lee S J, Vihokhern B, Kunasol C, Imwong M, Tarning J, Taylor W J, Yeung S, Woodrow C J, Flegg J A, Das D, Smith J, Venkatesan M, Plowe C V, Stepniewska K, Guerin P J, Dondorp A M, Day N P and White N J (2014) Spread of artemisinin resistance in Plasmodium falciparum malaria $N$ Engl J Med 371 411-23

Bajpai R, Dutta G P and Vishwakarma R A (1989) Blood schizontocidal activity of a new antimalarial drug, arteether (alpha/beta) against Plasmodium knowlesi in rhesus monkeys Trans R Soc Trop Med Hyg $\mathbf{8 3} 484$
Thanks are also due to Mr. K L Gupta for typing of the manuscript. Finally, my special thanks are due to Professor Peter Agre, Noble Laureate and Director, John Hopkins Malaria Research Institute, USA for his valuable support and encouragement to our Antimalarial Drug Discovery Programme.

Full Report available as Supplementary material here

Bhatt K M et al. (1996) Efficacy and tolerability of a sequential artesunate suppository - Mefloquine treatment of severe malaria. Jpn J Trop Med Hyg 24 (Suppl 1) 59-63

Cao X T, Betheill D B and Pham T P, Ta T T, Tran T N, Nguyen T T, Pham T T, Nguyen T T, Day N P and White N J (1997) Comparison of artemisinin suppositories, intramuscular artesunate and intravenous quinine for the treatment of severe childhood malaria Trans $R$ Soc Trop Med Hyg 91 465-467

CDRI Patent (2000) Aablaquin (Combination of Bulaquine and Chloroquine) 501/ MuM/2000/Grant date 21.05.2000

Dende C, Meena J, Nagarajan P, Panda A K, Rangarajan P N and Padmanaban G (2015) Simultaneously targeting inflammatory response and parasite sequestration in brain to treat experimental cerebral malaria Scientific Reports 5 12671

Dondorp A M, Nosten F, Yi P et al. (2009) Artemisinin resistance in Plasmodium falciparum malaria N Engl J Med 36 145567

Dondorp A, Nosten F, Stepniewska K, Day N, White N et al. (2005) Artesunate versus quinine for treatment of severe falciparum malaria: a randomized trial Lancet $\mathbf{3 6 6}$ 717-725

Douglas N M, John G K, von Seidlein L, Anstey N C and Price R N (2012) Chemotherapeutic strategies for reducing transmission of Plasmodium vivax malaria Advances in Parasitology 80 271-300

Dutta G P and Tripathi R (1996) Arteether $\alpha / \beta$ - a fast acting antimalarial Jpn J TropMed Hyg 24 (Suppl 1) 65-69

Dutta G P and Tripathi R (2003) New antimalarial drug development in India Arteether $\alpha / \beta$ - a blood schizontocide Proc Indian Natn Sci Acad B 69 861-870

Dutta G P, Bajpai R and Vishwakarma R A (1987) Blood schizontocidal activity of artemisinin (Qinghaosu) and a new antimalarial arteether against Plasmodium berghei Indian J Parasitol 11 253-257

Dutta G P, Bajpai R and Vishwakarma R A (1989a) Comparison of antimalarial efficacy of artemisinin (Qinghaosu) and arteether against Plasmodium cynomolgi B infection in monkeys Trans R Soc Trop Med Hyg 83 56-57 
Dutta G P, Bajpai R and Vishwakarma R A (1989) Antimalarial efficacy of arteether against multiple drug resistant strain of Plasmodium yoelii nigeriensis Pharmacol Res 21415 419

Dutta G P, Bajpai R and Vishwakarma R A (1988) Comparison of antimalarial efficacy of artemisinin (Qinghaosu) and arteether against Plasmodium cynomolgi B infection in monkeys Trans R Soc Trop Med Hyg 83 56-57

Dutta G P, Bajpai Renu and Vishwakarma R A(1989b) Artemisinin - A new gametocytocidal drug for malaria Chemotherapy (Basel) 35 200-207

Dutta G P, Puri S K, Bhaduri A P and Seth M (1989c) Radical curative activity of a new 8-aminoquinoline derivative (CDRI compound 80/53) against Plasmodium cynomolgi B in monkeys Am J Trop Med Hyg 41 635-637

Dutta G P, Mohan A and Tripathi R (1990) Study of the gametocytocidal/sporontocidal action of qinghaosu (artemisinin) by electron microscopy J Parasitol 76 84952

Dutta G P et al. (2001) Synergistic anti-malarial formulation United States Patent No. 6,326,023, December 4, 2001

Dutta G P, Puri S K, Awasthi A, Mishra M and Tripathi R (2000) Pyronaridine An effective antimalarial against multidrug resistant malaria Life Sciences 67 759-763

Dutta G P and Puri S K (2003) New Antimalarial drug development in India: radical curative agents CDRI 80/53 (Elubaquine) and WR 238605 (Tafenoquine) Proc Indian Nat Sci Acad B 69 871-882

Eckstein-Ludwig U, Webb R J, Van Goethem I D et al. (2003) Artemisinins target the SERCA of Plasmodium falciparum Nature 424 957-61

Flannery E L, Chatterjee A K and Winzeler EA(2013) Antimalarial drug discovery (MDASH) approaches and progress towards new medicines Nature Reviews Microbiology 11 849-62. doi: 10.1038/nmicro3138

Gogtay N J, Kamtekar K D, Dalvi S S et al. (2006) A randomized, parallel study of the safety and efficacy of $45 \mathrm{mg}$ primaquine versus $75 \mathrm{mg}$ bulaquine as gametocytocidal agents in adults with blood schizonticide-responsive uncomplicated falciparum malaria (ISCRTN50134587) BMC Infect Dis 6 16 (doi : 10.11.86/1471-2334-6-16)

Gomez-Landires E A (1996) Efficacy of artesunate suppository followed by oral mefloquine in the treatment of severe falciparum malaria in endemic areas where resistance to chloroquine exists in Ecuador Jap J Trop Med Hyg 24 1724

Hastings I M and Ward S A (2005) Coartem (Artemether -
Lumefantrine) in Africa: the beginning of the end? J Infect Dis 192 1303-4

Hein T T, Tam D T, Cuc N T and Arnold K (1991) Comparative effectiveness of artemisinin suppositories and oral quinine in children with acute falciparum malaria Trans Roy Soc Trop Med Hyg 85 210-1

Hoffman F L (1917) A plea and a plan for the eradication of malaria throughout the Western Hemisphere, Newark, NJ Prudential Press

Indian Council of Medical Research (2014) Clinical drug trials : Epidemiology -update on $\alpha / \beta$-Arteether, Bulaquin (80/ 53) CDRI), Ayush-64, Azithromycin, Arterolane (Rbx11160), Artemether-Lumefantrine

Jain D C, Dutta et al. (2002) Dihydroartemisinin, US 6362219 B1 Patent

Krudsood S, Wilairatana P, Tangpukdee N et al. (2006) Safety and tolerability of elubaquine (bulaquine, CDRI 80/53) for treatment of Plasmodium vivax malaria in Thailand Korean J Parasitol 44 221-228

Li Y Q (1984) Effect of qinghaosu by rectal administration in the treatment of vivax malaria (in Chinese) Ji Shen Chong Bing Za Zhi 2279

Li G Q, Guo X B, Jian H X, Fu L C, Shen L C, Li R S, Dai B Q and Li Z L (1985) Observation on the efficacy of qinghaosu suppository in 100 cases of falciparum malaria $J$ Tradit Chin Med 5 159-161

Luxemburger C, Brockman A, Silamut K et al. (1998) Two patients with falciparum malaria and poor in vivo responses to artesunate Trans $R$ Soc Trop Med Hyg 92 668-9

Martensson A, Stromberg J, Sisowath C et al. (2005) Efficacy of artesunate plus amodiaquine versus that of artemether/ lumefantrine for the treatment of uncomplicated childhood Plasmodium falciparum malaria in Zanzibar, Tanzania Clin Infect Dis 41 1079-1087

Nandakumar D N, Nagaraj V A, Vathsala P G, Rangarajan P and Padmanaban G (2006) Curcumin-artemisinin combination therapy for malaria Antimicr Agents Chemother 50 18591860

Noedl H, Se Y, Schaecher K et al. (2008) Evidence of artemisininresistant malaria in western Cambodia N Engl J Med 359 2619-2620

Pratap R et al. (2007) Bulaquine Patent US 7183291, Feb 27, 2007. EP. 1055427, Oct 13, 2004

Puri S K and Dutta G P (2003) Blood schizontocidal activity of WR 238605 (Tafenoquine) against Plasmodium cynomolgi and Plasmodium fragile infections in rhesus monkeys Acta Tropica 86 35-40 
Puri S K and Dutta G P (1988) Studies on cyclic transmission of Plasmodium cynomolgi B and standardization of 3-day simian model for causal prophylactic activity Indian $J$ Parasit 12 99-107

Puri S K, Dutta G P, Milhous W K, Schuster B G and Davidson Jr D E (1994) WR 238605: A potential broad spectrum anti-malarial in Tropical Diseases: Molecular Biology and Control Strategies, pp 276-285 [eds S Kumar et al.] (CSIR: Publication and Information Directorate)

Puri S K and Dutta G P (1982) Antibiotics in the chemotherapy of malaria Progress in Drug Research 26 167-205

Puri S K, Srivastava R, Pandey V C, Sethi N and Dutta G P (1989) Methemoglobin toxicity and hematological studies on anti-relapse compound CDRI 80/53 and primaquine in dogs; Am J Trop Med Hyg 41 638-642

Puri S K and Dutta G P (2000) Causal prophylactic activity of non 8-aminoaquinoline compounds against sporozoiteinduced Plasmodium cynomolgi infection in Rhesus monkeys J Parasitic Diseases 24 67-72

Puri S K and Dutta G P (2005) Plasmodium cynomolgi: gametocytocidal activity of the anti-malarial compound CDRI 80/53 (elubaquine) in rhesus monkeys Exp. Parasitol $1118-13$

Reddy R C, Vatsala P G, Keshamouni V G, Padmanaban G and Rangarajan P N (2005) Curcumin for malaria therapy Biochem Biophys Res Commun 326 472-474

Ross Ronald (1902) Noble Prize Award in Physiology and Medicine (Malaria) https://en.wikipedia.org/wiki/ Ronald_Ross\#cite_note-35

Sahr F, Willoughby V R, Gbakima A A, Bockarie M J (2001) Apparent drug failure following artesunate treatment of Plasmodium falciparum malaria in Freetown, Sierra Leone: four case reports Annals of Tropical Medicine and Parasitology 95 445-449

Sethi N, Srivastava R, Murthy P S R and Singh R K (1988) Systemic toxicity study of a new schizontocidal antimalarial drug arteether in rats and monkeys Indian $J$ Parasitol 12 223-235

Sethi N, Srivastava S, Singh R K and Puri S K (1993) Long-term toxicity studies of a synthetic anti-relapse antimalarial compound CDRI 80/53 in rats and monkeys Indian $J$ Parasit 17 15-28

Sisowath C, Ferreira P E, Bustamante L Y et al. (2007) The role of pfmdr1 in Plasmodium falciparum tolerance to artemether-lumefantrine in Africa Trop Med Int Health $\mathbf{1 2}$ 736-742

Thwe Y et al. (1996) Artesunate suppository - Mefloquine tablets
(Plasmotrim, Rectocaps, Mefloquine, Lactab) in the treatment of malaria Jpn J Trop Med Hyp 24 (Suppl 1) 2532

Tripathi R, Dhawan S and Dutta G P (2005) Blood schizontocidal activity of azithromycin and its combination with á/ß arteether against multidrug resistant Plasmodium yoelii nigeriensis a novel MDR parasite model for antimalarial screening Parasitology 131 95-301

Tripathi R, Dutta G P and Klayman D L (1992) Sodium Bartelinate - a potential future drug for cerebral malaria Proc $13^{\text {th }}$ Intern Congress Trop Med and Malaria 2, Abst: p85, Thailand

Tripathi R, Dutta G P and Vishwarkarma R A (1990) Gametocytocidal activity of the antimalarial $\alpha / \beta$ arteether against Plasmodium cynomolgi B Am J Trop Med Hyg 43 571-575

Tripathi R, Dutta G P and Vishwarkarma R A (1991) Comparison of anti-malarial efficacy of $\alpha, \beta$ and $\alpha / \beta$-arteether against Plasmodium cynomolgi $\mathrm{B}$ infection in monkeys Am J Trop Med Hyg 44 560-563

Tripathi R, Dutta G P and Vishwarkarma R A (1996) Gametocytocidal activity of $\alpha / \beta$-arteether by oral route of administration Am J Trop Med Hyg 54 652-654

Tripathi R, Puri S K and Dutta G P (1996) Sodium $\alpha$-artelinate A new potential gametocytocide Exptl Parasitol 82 251254

Tripathi R, Vishwakarma R A and Dutta G P (1997) Plasmodium fragile: Efficacy of arteether $\alpha / \beta$ against cerebral malaria model Experimental Parasitol 87 290-292

Tripathi R, Umesh A, Mishra M, Puri S K and Dutta G P (2000) Plasmodium yoeliinigeriensis (MDR) - Efficacy of oral pyronaridine against multidrug-resistant malaria in Swiss mice Experimental Parasitol 94 190-193

Tripathi R, Vishwakarma R A and Dutta G P (2008) New antimalarial drug development: Pre-clinical status of $\alpha$ and $\beta$ artelinate as fast acting blood schizontocides Proc Indian Natn Sci Acad 74 111-117

Vathsala P G, Dende C, Nagaraj V A, Bhattacharya D, Das G, Rangarajan P N and Padmanaban G (2012) CurcuminArteether combination therapy of Plasmodiumbergheiinfected mice prevents recrudescence through immunomodulation PLoS One 7 e29442

Valecha N, Usha Devi, C Joshi, H, Sahi V K, Sharma V P and Shiv Lal (2000) Comparative efficacy of Ayush-64 vs chloroquine in vivax malaria Curr Sci 781120

Valecha N, Adak T, Bagga A K, Asthana O P, Srivastava J S, Joshi $\mathrm{H}$ and Sharma V P (2001) Comparative antirelapse efficacy 
of CDRI compound 80/53 (Bulaquine) vs primaquine in double blind clinical trial Curr Sci 80 561-563

Valecha N (2012) Role of research in malaria control in India: Malaria in Southeast Asia: Perspectives, progress and partnerships, National Institute of Malaria Research (ICMR), New Delhi

Vennerstrom J L, Arbe-Barnes S, Brun R et al. (2004) Identification of an antimalarial synthetic trioxolane drug development candidate Nature 430 900-904

Vishwakarma R A, Mehrotra R, Thakur R S, Dutta G P and Bajpai R (1989) A process of preparation of sodium/ potassium $\mathrm{p}$-[(12 $\alpha$-dihydroartemisinin-inoxy) methyl] benzoate (sodium/potassium $\alpha$-artelinate), a new water soluble antimalarial derivative of artemisinin (qinghaosu) Indian Patent 173339

Vishwakarma R A, Mehrotra R, Tripathi R and Dutta G P (1992) Stereoselective synthesis and antimalarial activity of $\alpha$ artelinic acid from artemisinin $J$ Nat Products 55 11421144

White N J (2008) Plasmodium knowlesi: the fifth human malaria parasite CID: 46 (Editorial Commentary)

World Health Organization (1998) Life in the $21^{\text {st }}$ Century- A Vision for all Report of the Director General, WHO, Geneva

World Health Organization (2010a) Facts on ACTs January 2006 Update (February 2010) Available at http:/www.who.int/ malaria/am_drug policies by region afro/en/index.html

World Health Organization (2010b) Guidelines for the treatment of malaria. $2^{\text {nd }}$ Edition, No. of pages 194, Publication date 2010, ISBN 9782241547925

World Health Organization (2012) Update on artemisinin resistance - April 2012, Global Malaria Programme

World Health Organization Malaria: QandA on artemisinin resistance (Issued 2013 and updated in February 2015)

World Health Organization (2014) Global Malaria Programme, $21^{\text {st }}$ May, 2014

World Health Organization (2015) Global Technical Strategy for Malaria 2016-2030 (Dr Margret Chan, Director General, WHO), pp 1-29.

\section{Appendix-I}

Global Malaria Eradication International AgendaUpdate

1. Anothony M P, Burrows J N, Dupac C S et al. (2012) The global pipeline of new medicines for the control and elimination of malaria Malar J 11316. http:/www.malariajournal.com./content 11/1/316

2. The mal/ERA Consultative Group on Drugs (2011) A Research Agenda for Malaria Eradication: Drugs. PLOS Med. 8(1) e1000402; doi:10.1371/Journal pmed: 1000402

3. Wells T N C, Alonso P L and Gutteridge W E (2009) New medicines to improve control and contribute to the eradication of malaria; Nature Reviews Drug Discovery, 8

4. WHO (2010) Guidelines for the treatment of malaria $2^{\text {nd }}$ Edition, World Health Organization, Geneva

5. Tanner M, deSavigny Don Malaria eradication back on the table Bulletin World Health Org. http://www.who.INT./BULLETIN/Vol. 86/2/07050633/en/.

6. Newman R D (15 March 2013) Developing the Global Technical Strategy for Malaria Control and Elimination 2016-2025. World Health Organization, Geneva

7. Strategic Action Plan for Malaria Control in India 2007-2012 (11 ${ }^{\text {th }}$ Five Year Plan) Directorate of National Vector Borne Disease Control Programme, DGHS, Min. Health and FW GOI.

8. Roll Back Malaria (21.03.2011). Malaria in the News 15-21.03.2010. http://www. rollbackmalaria.org/docs/malnews/mitn 11-0321.html.

9. Alonso P L, Brown G, Arevalso-Herrera M, Binka F, Chitnis C et al. (Jan 25, 2011) A Research Agenda to Underpin Malaria Eradication. PLOS Med 8(1), e1000406, doi 10.1371/Journal pmed 1000406

10. World Health Organization (2010) Geneva: World Health Organization Available: http:// whqlibdoc.who.int/publications/20.10/ 9789241564106_eng.pdf.

11. Roll Back Malaria Partnership (2008) The global malaria action plan for a malaria free world. Geneva RBM. Available http://www.int/ publications/20:10/9789241564106-eng.pdf

12. Bill and Melinda Gates Foundation: Goal: 1. To 
control, eliminate and ultimately eradicate malaria (2003); 2. Global Development. http:// www.gatesfoundation. Org./What-We-Do/ Global-Health/Malaria. http:www.theguardian. com/world/ 2006/jan/03/g8.internationalaid-and development.

13. Mendis K, Rietveld A, Warsame M, Bosman A, Greenwood B et al. (2009) From malaria control to eradication: The WHO perspective. Trop Med Int Health 14:802-809. Doi910.1111/j 1365-3156 2009.02287x.

14. Feachem R G A, Phillips AA, Targett GAEditors (2009) Shrinking the malaria map. A prospectus on malaria elimination San Francisco : The Global Health Group, Global Health Sciences University of California, San Francisco

15. Greenwood B, Fidock D A, Kyle D E, Kappe S H, Alonso P L et al. (2008) Progress, perils and prospects for eradication; J Clin Invest 118, 1266 doi:10:1172/JC13996

16. S Abdulla, P Agre, PL Alonso, M ArevaloHerrera, Q Bassat, F Binka,C Chitnis, G Corradin, AF Cowman, J Culpepper, $\mathrm{H}$ del Portillo, RR Dinglasan (2011) A research agenda for malaria eradication: Vaccines PLoS Med 2011

17. The malERA Consultative Group on Modeling (2011) A research agenda for malaria eradication: Modeling PLoS Med 8: e1000403. doi: 10.1371/journal.pmed.1000403

18. The malERA Consultative Group on Vector Control (2011) A research agenda for malaria eradication: Vector control PLoS Med 8: e1000401. Doi:10.1371/journal.pmed.1000401

19. The malERA Consultative Group on Diagnoses and Diagnostics (2011) A research agenda for malaria eradication: Diagnosis and Diagnostics PLoS Med 8: e 1000396. doi:10.1371/ journal.pmed.1000396

20. The malERA Consultative Group on Integration Strategiers (2011) A research agenda for malaria eradication. Cross-cutting issues for eradication. PLoS Med 8: e1000404. doi:10.1371/ journal.pmed.1000404
21. The malERA Consultative Group on Basic Science and Enabling Technologies (2011) A research agenda for malaria eradication: Basic science and enabling technologies PLoS Med 8:e1000399. doi:10.1371/journal.pmed.1000399

22. Tanner M, de Savigny D (2008) Malaria eradication back on the table; Bull. World Health Organ 86 82-83. Doi:10.2471/BLT.07.050633

23. The malERA Consultative Group on Health Systems and Operational Research 2011 A research agenda for malaria eradication: Health systems and operational research PLoS Med8: e1000397. Doi:10.1371/journal.pmed.1000397

24. The malERA Consultative Group on Monitoring, Evaluation, and Surveillance 2011 A research agenda for malaria eradication: Monitoring, evaluation, and surveillance. PLoS Med 8: e1000400. Doi:10.1371/journal.pmed.1000400

25. Liu J, Modrek S, Gosling R D and Feachem R G A (July 2013) Malaria Eradication: Is it possible? Is it worth it? Should we do it? The Lancet Global Health 1 Pages e2-e3

26. The President's Malaria Inititiave (2013) Working group on value for money: An Agenda for Global Health Funding Agencies. Global Health Policy Program, Center for Global Development, http://www.cgdev.org./section/ topics/global_health/working_groups/value_for -money

27. CDC: US Govt.: Centers for Disease Control and Prevention: Malaria Worldwide How can Malaria Cases and Deaths be reduced. Use of Antimalarials to Reduce Malaria Transmission. Impact of Malaria

28. President's Malaria Initiative (PMI): U.S. Government Initiative. PMI's Partners. 1. U.S. Agency for International Development (USAID) CDC and 2. Global fund to Fight AIDS, TB, and Malaria. 3. The World Bank. 4. Roll Back Malaria. 5. UNICEF. 6. Organizations in Host-Countries. 7. PMI is at work in 19 countries in Sub-Saharan Africa and one Region in Asia - The Greater Mekong Sub-region 
29. DNDi: WHO. The Drugs for Neglected Diseases

30. The Carter Center for Malaria Control Program (2007) Waging Peace. Fighting Disease

31. Malaria Eradication Scientific Alliance (MESA)
(2013) Project ISGLOBA2 (Barcelona Institute of Global Health)

32. Jessica T Lin, Jonathan J Juliano and Chansuda Wongsrichanalai (2010) Drug-Resistant Malaria: The Era of ACT. Curr Infect Dis Rep 12(3), 165-173 